he named iodized lime. The salt in its dry state is probably a hypoiodite of lime. Diffused in hot water, a clear solution of iodate of lime and iodide of calcium is formed, and the excess of the lime is precipitated.

The rationale of this transformation appears to be as follows : A portion of lime parts with its oxygen to a portion of the iodous acid of the hypoiodite, and forms iodic acid $\left(\mathrm{I} \mathrm{O}_{5}\right)$, which, combining with its equivalent of lime, forms iodate of lime ( $\left.\mathrm{Ca} \mathrm{O}, \mathrm{I} \mathrm{O}_{5}\right)$, and the portion of calcium thus set free, combining with its equivalent of iodine, constitutes the iodide of calcium.

In the clear solution the presence of free lime, iodate of lime, and iodide of calcium are detected by the usual tests, besides a small quantity of iodoform. That the solution contains all the jodine is proved by none of it remaining in the deposit. A solution of uniform strength is obtained by employing defiuite proportions of iodine and lime in preparing the salt. The proportions are one part of iodine to seven parts of lime, so that one drachm of the salt contains about eight grains and a half of iodine; and in the proportion of one drachm of the salt to one pint of water a fluid ounce of the solution contains half a grain of pure iodine in the state of the above-mentioned combinations.

For the purpose of inhalation, external application, and internal administration, this salt affords an inexpensive and convenient mode of employing iodine.

For inhalation, one drachm of the salt diffused in one pint of boiling water, adding one drachm of diluted sulphuric acid to the clear solution poured off from the deposit. The watery vapour containing the iodine may be collected and inhaled through a glass or porcelain funnel inverted over the basin containing the hot solution, with or without the addition of tincture of conium or henbane. But the easiest and safest mode of inhalation is by surrounding the patient with an iodized atmosphere. This is done by rubbing the chest with the following liniment:- Half a drachm of the salt mixed with one ounce of soap-liniment, pouring off the clear part from the deposit, or with an ointment made by mixing one drachm of the salt with one ounce of lard.

For internal administration, one drachm of the salt may be diffused through one pint of boiling water; when cold, decanting off the clear solution, and keeping it in a well-closed bottle. Dose, half a fluid ounce, with two drachms of the compound fiuid extract of sarsaparilla, or one ounce of a bitter infusion, one hour or two after food.

It is incompatible with the vegetable and mineral acids, which precipitate the iodine, and with the alkaline carbonates which throw down the lime.

It is true that the quantity of iodine in the solution is minute, half a grain only of pure iodine in the ounce. But this is an advantage, the introduction of mineral substances into the system being more readily effected by, small than by large doses, which, by inflaming the mucous membrane of the alimentary canal or the cutaneous surface, close the orifices of the absorbents, and bar the entrance of the remedy. The question is not how large a dose or how large a quantity of an active agent the constitution of a patient will bear, but how small a quantity is sufficient to effect the cure of a disease; and that there are medicinal as well as natural diseases every day's experience tends to prove; neither can there be a doubt that medicines which are potent to cure disease are equally potent to cause disease, thongh of a totally different kind

The action of iodine upon the body is so well understood that it is unnecessary to enter upon the consideration of this subject. I may, however, mention a few of the intentions for which this preparation is extensively used at the Bloomsbury Dispensary.

1. As an inland succedaneum for sea-air in cases of scrofula and general debility, or, in combination with iron, in chlorotic and anmmic diseases

2. As a deobstruent and absorbent of hypertrophied structures and tuberculous deposits. The liniment externally and the solution internally have been successfully employed in the early stage of phthisis, with or without cod-liver oil.

3. As an antidote for metallic poisons - inercury, lead, copper. Hence the efficacy of the solution in muscular tremors, in neuralgia, and rheumatism of internal organs and external parts caused by these poisons. The evidence of their presence in the system is obtained from the history of the case and from the appearance of the free margin of the gums, which is red in mercurial, blue in leaden, and green in cupreons poisoning. The modus operand $i$ of the iodine is probably by uniting with these metals in the blood and tissues, and promoting their expulsion from the body.
The patients at the dispensary affected with one or other of these forms of constitutional poisoning are numerous, and I hope at some future period to publish a sufficient number of them to establish the efficacy of iodine in relieving a large class of sufferers under a hitherto hopeless and intractable form of disease.

Montague-street, Russell-square, November, 1835.

\section{ON A CASE OF GUN-SHOT WOUND.}

By WILLIAM LONEY, Esq., M.R.C.S.E.

On the 28th of August, 1855, I was called to see a case just brought into the Macclesfield workhouse, to which $I$ am surgeon. The patient, W. M-_ aged fifteen years, had been shot by a boy with a rifle bullet at two yards' distance. Blood was flowing from a wound in the inner angle of the left eye, and he was evidently suffering great pain, though in a state of partial insensibility, perhaps from the loss of blood. On the following day he was able to tell me that the bullet was in his head. The sight of the right eye was gone, and although the left was uninjured, he was several days before he could open it. On the 7th of September, I succeeded in extracting the ball from the back of the head; it was lying on the occipital bone. He died on the 10th of October greatly emaciated, being sensible to the last moment, and in no degree paralysed; having lived forty-three days in a state of great agony.

On making a post-mortem examination ten hours afterwards, I found bloody points in the medullary portion of the brain, all the ventricles filled with pus. I traced the wound from the inner angle of the left eye through the sphenoid bone and squamous portion of the temporal bone, throngh the right ventricle of the brain to the external wound or opening about one inch above the tip of the helix. A small fragment of bone was driven under the scalp round to the protuberance of the occiput. The opening in the skull was jagged and irregular. IIacclesfield, November, 1855 .

\section{antrotial Soutitis.}

\section{ROYAL MEDICAI \& CHIRURGICAL SOCIETY.} TuEsday, Nov. $27 \mathrm{TH}, 1855$. Mr. Chesar Hawkins, President.

ON THE ACTION OF DIGTTALIS UPON THE UTERUS. BY W. HOWSHIP DICKENSON, MSQ., LATE OBSTETRIC ASSYSTANT AT ST. GEORGE'S HOSPITAL. (Communicated by Dr. Bence JoNrs.)

THE writer commenced his paper by stating that during the month of October, 1854, a patient in St. George's Hospital, labouring under most severe menorrhagia, was cured by the infusion of digitalis, exhibited for the relief of cardiac affection, from which she also suffered. In consequence of this, he had been induced to try the remedy, by the permission of Dr. Lee, in a series of cases of uterine hæemorrhage which had occurred in the hospital. These cases, of which a table was given, were seventeen in number, and the general results of their treatment was as follows:- In every case of uterine hæmorrhage, unconnected with organic disease, requiring the employment of active remedies, admitted into the hospital after October, 1854, the administration of digitalis was had recourse to as the sole treatment, and the discharge was invariably arrested by it. The time which elapsed before the hrmorrhage subsided varied with the dose in which the digitalis was exhibited. When large doses were given, as an onnce to an ounce and a half of the infusion, the discharge never appeared after the second day; when smaller doses, it never continued beyond the fourth day. In uterine hæmorrhage connected with organic disease, the remedy acted with less certainty; its exhibition was required for a longer time, and the effect was sometimes transient. The author then spoke of the mode in which the digitalis operated in controlling uterine hæmorrhage; and after concluding that its effect could not depend on the sedative influence of the drug in the heart and arteries, he showed, by various experiments and observations, that the arrest of the hæmorrhage was due to the action of the digitalis on the ganglia of the uterus, by which the organ was stimulated, and the muscular substance powerfully contracted. 